\title{
The Impact of Flexible Benefits Plan on Organization Commitment and Intention to Quit
}

\author{
Dr. Zoubeir Ayache (professor) \\ Department of management and business administration \\ University Larbi Ben Mehidi,Oum El Bouaghi, Algeria \\ zoubeirayache@yahoo.fr \\ Ghennam Naima ( assissatant professor) \\ Department of management and business administration \\ University Larbi Ben Mehidi, Oum El Bouaghi, Algeria \\ Naimakati@hotmail.fr
}

\section{Doi:10.5901/mjss.2014.v5n8p136}

\begin{abstract}
In the past decade, the employee benefits industry has undergone considerable change with regard to the types of benefits available at the workplace. Plan sponsors have experimented with a variety of strategies to developing creative ways to tailor their benefit plans to the varying needs of employees. One approach set up is the flexible benefits plans. Thus, the focus of this paper is to develop economic study, test the relationship between benefits plan (traditional and flexible) as independent variables and organization commitment, employees' intention to quit as dependent variables on one side, on the other side we test these relationship according to the employees' demographic characteristics as control variables, with data from a sample of BHP company in Algeria and in headquarters in Australia, a total of 330 respondents were randomly selected as the sample of the study, data was analyzed by (IBM SPSS statistics 20), the study is divided into two parts. In the first part, our result prove that both of traditional benefits plan and flexible benefits plan are related with organization commitment and intention to quit, but the workers under flexible benefits plan demonstrated a higher commitment and lower intention to quit than traditional plan. The second part, the results also show that the demographics characteristics can play important role in the determining of employees' behavior, we prove that there is different in term of commitment and intention to quit among employees according to the differences in the demographic characteristics.
\end{abstract}

Keywords: Traditional benefits plan, flexible benefits plan, organization commitment, intention to quit, demographic characteristics.

\section{Introduction}

\subsection{Research background}

In today's day and age, compensation packages have evolved to include perks and benefits that were unheard of a generation ago. With the world progressing and people's wants and needs shifting, in order to stay competitive in order to attract, retain and motivate the kind of people who are committed to the success of an organization, it may necessitate a complete flexible compensation system. "Rethink, redesign and rebuild." This is what came by 2010 World Economic Forum in Switzerland, employers also need a program that help increase productivity and reduce costs but traditional programs don't reward employees for cutting costs or increasing profits, flexible benefit plans, have responded to this need. Over the last 35 years, flexible benefit plans have gradually appeared in response to this growing diversity in the North American workforce, Canada, and Europe.

Research results suggest that employee motivation is enhanced in the presence of a flexible benefit plan and that flexible benefit plans may increase employee satisfaction [21] and [1]. Advocates have also argued that these plans can help firms increase employee understanding of benefits and unify benefit programs, more frequently mentioned is the argument that these plans can help firms contain costs [14].

\subsection{Problem statement}

Employees who were satisfied with the benefits they received were more likely to be committed to the organization. Studies show that the absence of adequate benefits and efficiency reward program for employees contributes to his 
dissatisfaction [31]. However, the employees must understand how their involvement and attitudes affects the company's profits. On the other hand, employers are more concerned with the impact benefits may have on their company and its profitability.

This research intends to investigate whether the flexible benefits could give more impact on employees' attitude in term of enhancing commitment and reducing intention to quit, we investigate also the role of demographic characteristics of employees in this relationship.

\subsection{Research significance}

Our research aimed to make evident and to understand the response of workers toward organization after the implementation of the flexible benefits plan, in order to emphasize the importance of this program on individuals and organization. We wanted to test whether FBP had an influence on the employees' behavior toward its organization. Likewise, we wanted to test in which aspect this influence is appeared. In this paper we deal with the following topics; in the first stage we investigate the impact of traditional plans and flexible plan on organization commitment and intention to quit, and we compare which of those plans can enhance more the commitment and reduce more intention to quit. In the second stage we set the difference of the workers behavior according to them demographic characteristics.

The significance of the research is:

- A study of employee benefits can provide meaningful information and to create better understanding on the variables that may lead to the organization commitment, reducing intention to quit.

- A better insight on the influence of demographic background towards research' out- come variable (organization commitment, intention to quit),

- Understand the advantages can be gained by organizations from providing employees with benefits choice,

- Help in taking decisions about the adopting of this option, thus it help managers in the future planning process.

\subsection{Research objectives}

The purpose of this study is to highest the understanding of employee behavior toward organization under FBP, and gives some suggestions for future researches are presented. Specifically we seek:

- To identify the types of benefits can be given by the employer,

- To explore the relationship between employee benefits (flexible benefit plan and traditional benefit plan) and the following outcomes variables are summarized; employee commitment, intention to quit,

- To identify the demography background (gender, age, marital status, independent, education degree, and tenure),

- To explore the impact of demography background on organizational commitment and intention to quit,

- Try to find some solutions to current problems in Algeria Company by highlighting the role and importance of adopting flexible benefits plan as part of compensation system in enhancing employees and its benefits to organizations.

\section{Literature Review}

\subsection{Employees' benefits}

In an organization perspective, compensation is often viewed as an important human resource management function where it emphasizes planning, organizing, and controlling various types of pay systems [9]. Indirect financial compensation which is called benefit; it can be defined as all employers provided reward and services, other than wage or salaries [18]. According to [16] and [3] Under the traditional benefits plan, all employees are given the same fixed bundle of benefits that is usually decided by the firms without employees' involvement and output; these benefits suppose to meet the perceived needs [21]. However in today's day and age, compensation needs to update its packages. Studies also have shown that many variables such as age, sex, marital status, number of dependents, and years of services, can influence employee preferences for certain rewards [17], [8] according to demographic variables, satisfaction and organizational commitment are also varies from person to person $[29,11]$. Studies have also shown that the more progressive organization needs the more flexible structure [12]. New approaches is more consideration to this change is 
flexible benefits plan [9], Cafeteria plans provide a "menu", or choice of benefits from which employees select [7] and [5]. As [33] define flexible benefit plans as those that offer employees a choice between qualified (nontaxable) benefits and cash. FBPs have been on the increase in organizations to give employees more say over the conditions of their job, and to make the benefits better suited to the diversity of life-styles of their employees.

\subsection{Employees' benefits satisfaction}

Pay satisfaction and attitudes towards benefits have emerged as popular variables for use in organizational research [6]. Research has shown that to influence employee attitudes is the perception of the benefits offered by organization, pay and benefits [31] and [20], which in turn leads to strong organizational performance [8]. As also [16] and [27] found that the compensation schemes may influence employees' motivation, job attitudes, and behaviors and thus influence job satisfaction, productivity [30], staff retention and maintain competition [28]. The logic underlying employer strategies to voluntarily provide benefits suggests that benefit offerings are associated with employee benefit satisfaction, which in turn is associated with attitudes and behaviors that serve the employer's interests [22].

Benefit satisfaction is important because of its potential links with other important constructs such as organizational commitment and organizational citizenship behaviors [16], pay satisfaction has been shown to be related to behavioral outcomes such as absenteeism and turnover [32,2]. Thus, an understanding of benefit satisfaction may lead to an increased understanding of other important employee attitudes and behaviors. This relationship between the benefits and employee satisfaction incorporates contributions from two-factor theory, need theories, intrinsic motivation theories and equity theory [30], hence its strength. Thus based on social exchange, is that when employees are satisfied with benefits provided to them, they are committed to the employer, remain with the employer, and perform their jobs well, which in turn leads to strong organizational performance [32].

\subsection{Employee' benefits and organization commitment}

One of the challenges facing modern organizations involves maintaining employee commitment in the current business environment. Findings suggested that mandatory and fringe benefits and also family-responsive benefits were having significant and positive relationship with organizational commitment [22]. Studies have found that in general benefits facilitate organizational attachment by increasing organizational commitment [3], also lowering intentions to turnover [2]. As [21] and [18] show that employees' perceptions about their benefits are related to job satisfaction and organizational commitment, Theory suggests two ways in which benefits might influence commitment and turnover.

As [5] used data collected in a national survey of over 1500 US workers to examine the relationship between the availability of family responsive benefits and affective organizational commitment, they found a positive correlation between the availability of such benefits and commitment, even for those who would not benefit directly, they also argue that organizations that offer such benefits are perceived by employees as showing greater care and concern, and as being fair in their dealings with employees[7].

\subsection{Employees' benefits and intention to quit}

Organizational commitment (OC) has been conceptualized and measured in various ways, several studies have confirmed the important role of $(\mathrm{OC})$ as a major antecedent of intention to leave; they found a significant negative relationship between organizational commitment and intention to leave [25] they suggest that employees who are strongly committed are those who are least likely to leave the organization. The relationship between compensation fairness and organizational commitment is expected to be positive; the relationship between organizational commitment and turnover intent is expected to be negative. In a 1991 study of managers, reported that pay equity perceptions had an indirect impact on voluntary turnover via pay satisfaction, organizational commitment, and turnover intent $[2,20]$. In 1999, [Igalens and Rousel] found that offering employee benefits makes good business sense and thus significantly increases retention and reduces intention to quit [32]. In fact, the study concluded that the impact of providing benefits reduced turnover even further among companies that employed great numbers of part-time workers. By offering employees benefits, along with traditional benefits companies are better able to manage their employee intention to quit and thus reducing turnover rates [12]. According to [32] and the studies of [4, 13] suggest that benefits are a more powerful tool for reducing intention to quit and turnover. As $[10,8]$ proposed intermediate linkages in the process model describing the job satisfactionemployee intention to quit relationship. Benefit plans can enhance satisfaction, sustain loyalty, retain frontline workers, 
improve service quality and discourage employees from leaving [16]. Firms that offer attractive benefit packages tend to retain talented employees and reduce employee turnover [13].

\subsection{Flexible benefits plan and employee satisfaction}

Give the employees the ability to select compensations package they prefer from groups of benefits established by the employers improving the ability of employee to make its own decision [12], [30]. According to [7] and [15] found that Flexible plan may enhance satisfaction by making employees more aware of the nature and value of them benefits, employees are often unfamiliar with the value of their benefits packages, either in absolute terms or relative to the benefits received by others [21] [20], Flexible benefits plans promote an ethical organizational climate because the traditional plan ensures fairness by providing all employees with the same benefits while the flexible plan ensures quality of work life by providing employees with choices plan [33], [24] . Different in age, education, tenure, salary level and degree of family responsibility were also related to benefits satisfaction [11]. Thus, the perceived value of benefits from flexible plans should be higher compared to those in traditional plans as individuals choose only those benefits that they think they will utilize. One of few studies that directly involved flexible benefits examined the impact that adopting a FBP has on benefits satisfaction [15], they found that benefits satisfaction and understanding of benefits increased after the implementation of the flexible benefits plan. They maintain that the benefits satisfaction is a multidimensional construct comprising facets that reflect benefits coverage, adequacy and knowledge [19]. The flexible plan should enhance ethics more as alternatives are made available to employees to overcome the constraints faced in the traditional plan [7]. A cafeteria- style benefits plan is also expected to solve many problems because employees are often given flex points spend on the benefits that they want, the opportunity to choose benefits options makes the value of each option salient to employees [21, 22]. Current research linking flexible benefits with benefits satisfaction have shown inconclusive results $[15,29]$. As they found that when employees are allowed to participate in their organization's decision-making processes, they often developed positive attitudes toward the organization, as well as they are committed to the employer, remain with the employer, and perform their jobs well, this in turn leads to strong organization performance [21]. But the research that established that is a few.

The reason about the positive relationship between the FBP and satisfaction is that the perception of FBP enhances distributive justice perception based on need because these plans address each individual employee's specific need [19], whereby employees can choose benefits that are particularly relevant to their personal circumstance. In general, perceptions of organizational justice affect a number of attitudes, such as organizational commitment [7] and [2] and intentions to quit [13], as [7, 15] found that flexible benefits enhanced employee' feelings of commitment but [33] found no significant relationships. Similarly, [4] indicated that benefits satisfaction was negatively related to turnover intentions, but other found no significant relationships, as a result of these conflicting results, there is a need to further test these relationships. Thus, according to the positively associate between flexible benefits and procedure justice and satisfaction and these positively related to commitment and negatively to intention to quit we assume that the FBP will be positively related to higher levels of organizational commitment and lower intentions to quit. Thus, we examine if employees' satisfaction with their benefits and their perceptions of the value of their benefits are associated with higher levels of commitment and loyalty [4] and [25].

In this study and based on these theoretical we examine the relationship between the benefits program based on flexible benefits plans and employees behaviors toward their organization concerning commitment, intention to quit and the effect of demography variables in order to determine the differences and confirm the importance of the flexible benefits plan compare with traditional plan.

\section{Research Methodologies}

\subsection{Statistic methods:}

The research methodologies used as the descriptive manner relation studies, the statistical methods used are the arithmetic mean, standard deviation, percentage, median, correlation coefficient, Cronbach's alpha, linear regression.

\subsection{Data:}

The target population of this study was employees who are working in BHP Billiton Integrated Development company in Algeria, we collect and disaggregate data by gender, age, marital status, education background and tenure. 


\subsection{Interview and questionnaires}

There are three parts to our survey. The first part refers to the demographics of our participants, where they are asked about their gender, age, marital status, if they have children, education level and tenure or position in the company.

In the second part, there are 25 questions relating to employees' commitment in this part of the survey, we are using the questionnaires developed by Mowday, 1971 Organizational Commitment Questionnaire (OCQ) items Workers were to indicate whether they agree with these sentences that correspond to the perceptions of their existence in the company using a scale. The scale which ranges from (1) strongly disagree to (5) strongly agree, measures the degree to which employees are attached or committed to their organization.

Furthermore, the third component of our survey is comprised of 14 sentences regarding employee's intention to quit. Respondents were simply asked to indicate their agreement with the above items on a scale ranging from "strongly disagree" to "strongly agree".

\subsection{Hypothesis}

The following hypotheses are proposed

Hypothesis 1: traditional benefits plan will; a) positively related with organization commitment, b) Negatively correlated with employees' intention to quit.

Hypothesis 2: flexible benefit plan will a) positively related with organization commitment, b) Negatively correlated with employees' intention to quit.

Hypothesis 3: employees under flexible benefits plan have higher organization commitment than those under traditional plan.

Hypothesis 4: employees under flexible benefits plan have lower intention to quit than those under traditional plan.

As noted earlier, we rely upon demographic variables to define the employee risk profile and preference for benefit categories, older employees are more concerned about how their retirement accounts are shaping up; working parents are desperate for child care; younger workers want opportunities to move up the ladder fast. Gender, Age, marital status and years of employment are a set of properties that characterized one worker for others, but do these differences mean difference in the workers' response?

Thus, we suggest the following demographic information as the variable for study and we have proposed the following hypothesis:

Hypothesis 5: organization' commitment and intention to quit variables are related with the demographic characteristics of employees.

Hypothesis 6: there is no relationship between organization' commitment and intention to quit variables and demographic characteristics of employees.

\subsection{Descriptive analysis}

In order to obtain the desired results the data of this research is divided into three variables; independent variable, dependent variable, and control variable.

Independent variables The independent variable in this study is the type of benefits plan that the respondents were given, there are two types traditional benefits plan, and flexible benefits plan.

Dependent variables The both variable employees' commitment and employees' intention to quit will measured with an 8 items scale adapted an developed by [30] with five points Likert ranging scale with scores of one to five representing "strongly disagree", "disagree", "neither agree nor disagree", "Agree" and "strongly agree". Which 1 represent "strongly disagree", and 5 represent "strongly agree".

Control variables The demographic factors such as age, gender, marital status, tenure in the organization, and educational qualifications have been chosen as control variables.

\subsection{Data collection and analysis}

350 employees in BHP headquarter branch with FBP and 250 employees in BHP Algeria's 'branch with TBP were chosen as the samples of this study. To ensure confidentiality, no names or designations were asked. T tests between the demographic profiles of the employees of the two periods of time showed no significant differences in terms of the status, age, gender and educational qualifications at $p<0.05$. 


\subsection{Measurement Reliability}

For the items of organization commitment and intention to quit our results indicate that the scale are reliable with the Cronbach's alpha of 0.974 and 0.951 respectively according to the table 1 . Therefore, the mean value of these 25 items and 14 items was calculated for commitment and intention to quit respectively.

Table 1: Reliability statistics of commitment items and intention to quit item

\begin{tabular}{|l|c|c|c|}
\hline & Cronbach's Alpha & Cronbach's Alpha Based on Standardized Items & N of Items \\
\hline commitment & 0.974 & 0.975 & 25 \\
\hline Intention to quit & 0.951 & 0.95 & 14 \\
\hline
\end{tabular}

\section{Research Findings}

\subsection{The relationship between dependant and independent variables}

Generally the table 2 resume all the results we can see that under FBP the workers have high organization commitment $(M=3.81, S D=0.46)$ compare those under TBP $(M=2.93, S D=0.4)$, With regard to intention to quit, in general the workers under FBP indicated low level of intention to quit $(M=1.39, S D=0.53)$ compare with thus under $T B P(M=3.14$, $\mathrm{SD}=0.46)$.

Table 2: Mean and standard deviation of commitment and intention to quit under the two types of benefits

\begin{tabular}{|c|c|c|c|c|}
\hline \multirow{2}{*}{} & \multicolumn{2}{|c|}{ commitment } & \multicolumn{2}{c|}{ intention to quit } \\
\cline { 2 - 5 } & $\mathrm{M}$ & $\mathrm{SD}$ & $\mathrm{M}$ & $\mathrm{SD}$ \\
\hline TBP & 2.398 & 0.4013 & 3.142 & 0.4658 \\
\hline FBP & 3.81 & 0.4663 & 1.935 & 0.5399 \\
\hline
\end{tabular}

To insured more our results, two statistical tools were applied to the data; correlation and linear regression. The correlation of FBP is found to be strongly and positively associated with the organizational commitment as well as is found to be strongly and negatively associated with intention to quit ( BT and commitment, $r=0.835, p<=0.001$ and BT and intention to quit, $r=-0.746, p<=0.001$ ). It means that when the value of benefits is increasing from zero (TBP) to 1 (FBP) the organizational commitment may also increase but the intention to quit decrease.

Table 3: Correlation among variables: types of benefits, commitment and intention to quit

\begin{tabular}{|l|c|c|c|}
\hline & Benefits Type & Commitment & Intention to quit \\
\hline Benefits Type & 1 & & \\
\hline Commitment & $.835 *$ & 1 & \\
\hline quit & $-.746 * *$ & $-.795 * *$ & 1 \\
\hline
\end{tabular}

$*$ Correlation is significant at the 0.05 level (2-tailed). **Correlation is significant at the 0.01 level (2-tailed).

Table 4: Linear regression analysis for commitment and intention to quit

\begin{tabular}{|c|c|c|c|c|c|c|c|c|c|c|}
\hline \multicolumn{11}{|c|}{ Coefficients } \\
\hline & & \multicolumn{4}{|c|}{ commitment } & \multicolumn{4}{|c|}{ Intention to quit } & \multirow{3}{*}{ sig } \\
\hline \multirow{2}{*}{\multicolumn{2}{|c|}{ Model }} & \multicolumn{2}{|c|}{$\begin{array}{l}\text { Un-standardized } \\
\text { Coefficients }\end{array}$} & \multirow{2}{*}{$\begin{array}{c}\text { Standardized } \\
\text { Coefficients } \\
\text { Beta }\end{array}$} & \multirow[t]{2}{*}{$\mathrm{t}$} & \multicolumn{2}{|c|}{$\begin{array}{l}\text { Un-standardized } \\
\text { Coefficients }\end{array}$} & \multirow{2}{*}{$\begin{array}{c}\begin{array}{c}\text { Standardized } \\
\text { Coefficients }\end{array} \\
\text { Beta }\end{array}$} & \multirow[t]{2}{*}{$t$} & \\
\hline & & $B$ & Std. Error & & & $\mathrm{B}$ & Std.error & & & \\
\hline \multirow[b]{2}{*}{1} & Constant) & 2.398 & 0.04 & & 57.823 & 3.142 & .048 & & 65.377 & 0 \\
\hline & BT & 1.412 & 0.05 & .835 & 27.471 & -1.206 & .060 & -.746 & -20.264 & 0 \\
\hline
\end{tabular}

*Dependent Variables: commitment and intention to quit.

Model Summary

\begin{tabular}{|c|c|c|c|c|c|c|c|c|}
\hline & \multicolumn{5}{|c|}{ commitment } & \multicolumn{4}{c|}{ Intention to quit } \\
\hline Model & $\mathrm{R}$ & Adjusted R Square & Std. Error of the Estimate & $\mathrm{R}$ & $\mathrm{R}$ Square & Adjusted R Square & Std. Error of the Estimate \\
\hline 1 & $.835 *$ & 0.697 & 0.696 & 0.444 & $.746 *$ & .556 & .555 & .515 \\
\hline
\end{tabular}

*Predictors: (Constant), BT 
ANOVAs

\begin{tabular}{|c|c|c|c|c|c|c|c|c|c|c|}
\hline & \multicolumn{4}{|c|}{ commitment } & \multicolumn{3}{c|}{ Intention to quit } & \multicolumn{1}{c|}{} \\
\hline \multicolumn{2}{|c|}{ Model } & Sum of Squares & DF & Mean Square & $F$ & Sum of Squares & DF & Mean Square & $F$ & Sig. \\
\hline & Regression & 149.295 & 1 & 149.295 & 754.671 & 109.045 & 1 & 109.045 & $410.627 .000 *$ \\
\hline 1 & Residual & 64.888 & 328 & 0.198 & & 87.103 & 328 & .266 & & \\
\hline & Total & 214.183 & 329 & & & 196.147 & 329 & & & \\
\hline
\end{tabular}

*Dependent Variable: commitment and intention to quit

**Predictors: (Constant), BT

According to the linear regression analysis in the table 4 the intercept 2.398 and 3.142 is representing the estimated average value of organizational commitment and intention to quit when type benefit is zero. The slop of independent variables also exhibits useful information for the implication purposes. The slop of BT, which is 1.412 and -1.206, explain the change in organizational commitment and intention to quit when BT increases by 1 . Benefit type could significantly contribute towards the R2 value (0.697) and (0.556) which explains $70 \%$ and $55 \%$ variation in the employees' organizational commitment intention to quit. An examination of this variable indicated that the benefit type represented the strongest effect on organizational commitment with the standard beta 1. 412 and intention to quit with beta of -1.206 . Thus the statistical results prove that positive and strong linear relationships exist between dependent variable (commitment) and independent and strong negative linear relationships exist between independent variable and dependent variable (intention to quit). We can also prove that under FBP the commitment is higher and intention to quit lower than TBP. Linear regression line that predicted organizational commitment and intention to quit from two types of benefits by minimizing the sum of the square of the vertical distances of the points from the regression line. R2 $=0.697$ and R2 $=0.557$ measure goodness of the linear regression given as under

$$
\begin{aligned}
& y=\beta 0+\beta 1 \times X 1+\beta 2 \times X 2+\beta 3 \times X 3+\beta 4 \times X 4+\beta 5 \times X 5+\beta 6 \times X 6+\beta 7 \times X 7+x i \\
& \text { Organizational Commitment }=(2.398)+(1.412) B T \\
& \text { Intention to quit }=(3.142)+(-1.206) B T
\end{aligned}
$$

\subsection{The effect of demographic variables}

To test the effect of demographics characteristics on the organizational commitment and intention to quit, the correlation multiple regressions was run to explore the relation between the control variables and the dependent variables and the results shown in the table 5, but for our study we are interested about the row 8 and 9 which show the relationship between commitments and the demographic characteristics, the correlation of commitment is founded positively associated with the employee' gender, age, marital status, dependent and tenure with $r$ value $(r=.835 ; p=<0.01, r=.016$, $r=.109 ; p<0.05, r=.051, r=.040 r=.196^{\star *} ; p=<0.01$ ) respectively as well as is found to be negatively associated with employee' education degree $(r=-.013)$. the correlation of intention to quit is founded negatively associated with the employee' gender, age, marital status, dependent, and tenure with $r$ value $\left(r=-.746^{\star *} ; p=<0.01, r=-.025, r=-.083, r=\right.$ $\left..004, r=-.004 r=-.124^{*} p<0.05\right)$ as well as is found to be and positively associated with employee' education degree $(r=$ .058).

To test more the effect of demographics characteristics on the organizational commitment and intention to quit, the following multiple regression was run:

$$
y=\beta 0+\beta 1 \times X 1+\beta 2 \times X 2+\beta 3 \times X 3+\beta 4 \times X 4+\beta 5 \times X 5+\beta 6 \times X 6+\beta 7 \times X 7+\xi
$$

Table 5: Correlation among all types of variables

\begin{tabular}{|l|c|c|c|c|c|c|c|c|c|}
\hline & $\mathbf{1}$ & $\mathbf{2}$ & $\mathbf{3}$ & $\mathbf{4}$ & $\mathbf{5}$ & $\mathbf{6}$ & $\mathbf{7}$ & $\mathbf{8}$ & $\mathbf{9}$ \\
\hline Benefits Type & $\mathbf{1}$ & & & & & & & & \\
\hline Age & $-.132^{\star}$ & 1 & & & & & & & \\
\hline Gender & -0.006 & $-.363^{\star \star}$ & 1 & & & & & & \\
\hline Marital Status & -0.092 & $.550^{\star \star}$ & -0.032 & 1 & & & & & \\
\hline Dependent & -0.086 & $.583^{* \star}$ & -0.082 & $.886^{\star \star}$ & 1 & & & & \\
\hline Education Degree & 0.065 & $-.461^{\star \star}$ & $.288^{\star \star}$ & $-.238^{\star \star}$ & $-.253^{\star \star}$ & 1 & & & \\
\hline Tenure & -0.018 & $-.200^{\star *}$ & $.614^{\star *}$ & 0.071 & 0.006 & $.496^{* \star}$ & 1 & & \\
\hline Commitment & $.835^{\star \star}$ & 0.016 & $.109^{\star}$ & 0.051 & 0.04 & -0.013 & $.196^{\star \star}$ & 1 & \\
\hline QUIT & $-.746^{\star \star}$ & -0.025 & -0.083 & -0.004 & -0.004 & 0.058 & $-.124^{*}$ & $-.795^{\star \star}$ & 1 \\
\hline
\end{tabular}

*. Correlation is significant at the 0.05 level (2-tailed). $\quad$ **. Correlation is significant at the 0.01 level (2-tailed). 
Table 6: Linear regression of the demographic variables' effect on commitment and intention to quit under TBP Model Summary

\begin{tabular}{|c|c|c|c|c|c|c|c|c|}
\hline & \multicolumn{4}{|c|}{ commitment } & \multicolumn{4}{|c|}{ Intention to quit } \\
\hline Model & $\mathrm{R}$ & R Square & Adjusted R Square & Std. Error of the estimate & $\mathrm{R}$ & R Square & Adjusted R Square & Std. Error of the estimate \\
\hline 1 & $.632 *$ & .400 & .366 & .3195 & $.464 *$ & .216 & .172 & .4238 \\
\hline
\end{tabular}

*Predictors: (Constant), employee 'tenure, child, employee education, gender of employee, age (Binned), marital status ANOVAs*

\begin{tabular}{|c|c|c|c|c|c|c|c|c|c|}
\hline \multicolumn{2}{|c|}{} & \multicolumn{3}{|c|}{ commitment } & \multicolumn{2}{c|}{ Intention to quit } & \multicolumn{2}{c|}{ Sharing value } \\
\hline & Sum of Squares & Mean Square & $F$ & Sum of Squares & Mean Square & $F$ & DF & Sig \\
\hline 1 & Regression & 7.334 & 1.222 & 11.977 & 5.336 & .889 & 4.952 & 6 & $.000 * *$ \\
\hline & Residual & 11.022 & .102 & & 19.398 & .180 & & 108 & \\
\hline
\end{tabular}

*Dependent Variable: commitment **Predictors: (Constant), employee 'tenure, child, employee education , gender of employee, age (Binned), marital status

Coefficients*

\begin{tabular}{|c|c|c|c|c|c|c|c|c|c|c|c|}
\hline \multirow{4}{*}{\multicolumn{2}{|c|}{ Model }} & \multicolumn{5}{|c|}{ commitment } & \multicolumn{5}{|c|}{ Intention to quit } \\
\hline & & \multirow{2}{*}{\multicolumn{2}{|c|}{ Un-std Coefficients }} & \multirow{3}{*}{$\frac{\text { Std Coe }}{\text { Beta }}$} & \multirow{3}{*}{ t } & \multirow{3}{*}{ Sig } & \multicolumn{2}{|c|}{ Un-std Coefficients } & \multirow{3}{*}{$\begin{array}{c}\text { Std Coe } \\
\text { Beta }\end{array}$} & \multirow{3}{*}{$\mathrm{t}$} & \multirow{3}{*}{ Sig } \\
\hline & & & & & & & \multirow[b]{2}{*}{ B } & \multirow[b]{2}{*}{ Std. Error } & & & \\
\hline & & $B$ & Std. Error & & & & & & & & \\
\hline & (Constant) & 2.22 & .145 & & 15.299 & .000 & 3.322 & .193 & & 17.245 & .000 \\
\hline & Employee gender & .109 & .103 & .107 & 1.060 & .292 & -.049 & .136 & -.042 & -.362 & \\
\hline & age (Binned) & .035 & .046 & .082 & .759 & .450 & -.07 & 0.61 & -.143 & -1.158 & .250 \\
\hline & marital status & .105 & .177 & .104 & .595 & .553 & -.06 & .235 & -.053 & -.268 & .789 \\
\hline & child & .128 & .170 & .133 & .749 & .456 & -.05 & .226 & -.051 & -.251 & .802 \\
\hline & employee education & -.158 & .066 & -.246 & -2.414 & .017 & .26 & .087 & .347 & 2.987 & .003 \\
\hline & employee tenure & .239 & .040 & .673 & 6.017 & .000 & -.21 & .053 & -.519 & -4.057 & .000 \\
\hline
\end{tabular}

*Dependent Variable: commitment and intention to quit

Table 7: Linear regression of the demographic variables' effect on commitment and intention to quit under FBP Model Summary

\section{commitment \\ Intention to quit}

\begin{tabular}{|c|c|c|c|c|c|c|c|c|}
\hline Model & R & R Square & Adjusted R Square & Std. Error of the Estimate & R & R Square & Adjusted R Square & Std. Error of the Estimate \\
\hline
\end{tabular}

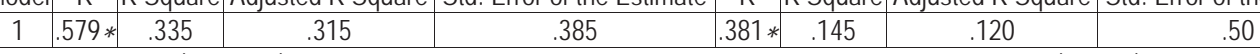

*Predictors: (Constant), employee 'tenure, child, employee education , gender of employee, age (Binned), marital status

ANOVAs*

\begin{tabular}{|c|c|c|c|c|c|c|c|c|c|c|}
\hline \multicolumn{2}{|c|}{} & \multicolumn{4}{|c|}{ commitment } & \multicolumn{3}{c|}{ Intention to quit } & \multirow{2}{*}{ Sig. } \\
\hline \multicolumn{2}{|c|}{ Model } & Sum of Squares & DF & Mean Square & F & Sum of Squares & DF & Mean Square & F & \\
\hline & Regression & 15.573 & 6 & 2.596 & 17.439 & 9.047 & 6 & 1.508 & 5.882 & $.000 * *$ \\
\hline 1 & Residual & 30.958 & 208 & .149 & & 53.321 & 208 & .256 & & \\
\hline & Total & 46.531 & 214 & & & 62.368 & 214 & & & \\
\hline
\end{tabular}

*Dependent Variable: commitment and intention to quit **Predictors: (Constant), employee 'tenure, child, employee education , gender of employee, age , marital status

\begin{tabular}{|c|c|c|c|c|c|c|c|c|c|c|}
\hline & & & Coeffici & $n t s *$ & & & & & & \\
\hline \multirow{3}{*}{ Model } & \multicolumn{5}{|c|}{ commitment } & \multicolumn{5}{|c|}{ Intention to quit } \\
\hline & \multicolumn{2}{|c|}{$\begin{array}{l}\text { Un-standardized Coefficients } \\
\text { Standardized Coefficients }\end{array}$} & \multirow{2}{*}{$\begin{array}{c}\text { Standardized } \\
\text { Coefficients }\end{array}$} & \multirow{2}{*}{ t } & \multirow{2}{*}{ Sig } & \multicolumn{2}{|c|}{$\begin{array}{l}\text { Un-standardized } \\
\text { Coefficients }\end{array}$} & \multirow[t]{2}{*}{$\begin{array}{c}\text { Standardized } \\
\text { Coefficients Beta }\end{array}$} & \multirow[t]{2}{*}{$\mathrm{t}$} & \multirow[t]{2}{*}{ Sig } \\
\hline & B & Std.Error & & & & B & Std. Error & & & \\
\hline (Constant) & 3.412 & .125 & & 27.31 & .000 & 2.165 & .164 & & 13.205 & .000 \\
\hline age (Binned) & .171 & .043 & .322 & 3.942 & .000 & -.160 & .057 & -.260 & -2.810 & .005 \\
\hline gender & .026 & .093 & .021 & .274 & .784 & -.135 & .122 & -.097 & -1.100 & 273 \\
\hline marital status & .044 & .127 & .043 & .350 & .727 & -.050 & .167 & -.041 & -.300 & .764 \\
\hline Child & .019 & .124 & .019 & .153 & .879 & -.139 & .162 & -.119 & -.855 & .394 \\
\hline Employee education & -.249 & .055 & -.326 & -4.511 & .000 & .236 & .073 & .266 & 3.254 & .001 \\
\hline employee tenure & .216 & .038 & .471 & 5.744 & .000 & -.139 & .049 & -.262 & -2.824 & .005 \\
\hline
\end{tabular}

*Dependent Variables: commitment and intention to quit

The results from the tables 5, 6 and 7 indicate that demographic variables could contribute towards the R2 values ( 0.4 and 
0.33) this variable could explain $40 \%$ and $33 \%$ variation in the employees' organizational commitment under TBP and FBP respectively. R2 value of ( 0.21 and 0.145$)$ could explain $21 \%$ and $14.5 \%$ variation in the employees' intention to quit under TBP and FBP respectively, we can see that the demographic variables has more effect under TBP, whereby under the FBP they have not that much effect. An examination of this variables indicated that the control variables represented the strongest effect on organizational commitment and intention to quit with the standard beta shown in the table. Thus the statistical results prove that positive relationships exist between dependent variable (commitment) and control variables (gender, age, marital status, dependent, tenure) where the value of beta is $(0.109,0.035,0.105,0.128$ and $0.239)$ for TBP and similarly for FBP where beta $(0.171,0.026,0.044,0.019,0.216)$, negatively relationship with (education) beta(-0.158 and -0.249 ) for TBP and FBP respectively.

For intention to quit the statistical results prove that negatively relationships exist between dependent variable (intention to quit) and control variables (gender, age, marital status, de- pendent and tenure) where the value of beta ($0.049,-.070-.063-.057-.213)$ for TBP and beta $(-0.16,-0.135,-0.050,-0.139,-0.139)$ and positively relationship with (education) beta ( 0.26 and 0.236 ) for TBP and FBP respectively.

\subsection{Research discussion and conclusion}

The theoretical contribution we make in this study can be divided into two main parts. First, the delineation between the two types of benefits perceived the traditional benefit plan and flexible benefits plan and employee attitude. We are able to show that both traditional and flexible benefits are having significant and positive relationship with organizational commitment and negative relationship with intention to quit, but the provision of flexible benefits has higher organization commitment and lower employee' intention to quit. Several possible explanations for this result can be suggested. The first possible explanation is the belief that the employee is engaged in a fair economic exchange, most employees felt that they got a fair chance of being promoted and were satisfied with their chances for promotion, other possible reason is that the employees may perceive that the total value of their benefits was significantly different and higher than traditional benefits, as result they value this reward system which reflected to them behavior this can support the Expectancy theory (Lawler, 1971) which recommend employer to use FBP to reward employees, another reason is that perhaps the employees feel that the selection of benefits give them the flexibility to meet them needs. Other possible explanation is that the FBP give the employees the feeling of participation in decision making process among the organization which enhance employees' belonging feeling and emotionally attached [20] and [24] and enhance commitment to organization [7]. The results obtained would increase employers' understanding on how to design and communicate employee benefits and provide benefits choices that would lead to sustained positive employee attitudes, yet minimize costs to employers.

Moreover, present study concludes that there is a significance difference in the attitude of employees according to difference in demographic characteristics; these results may provide meaningful perspectives for understanding of how individual's similarities and differences affect the behavior of workers toward organizations. Female, older, married, have dependent, and high tenure, less education level workers had higher levels of organizational commitment and lower intention to quit than male, younger, single, less tenure and higher education background.

In terms of practical contributions, HR managers may use these findings as a reference to plan effective compensation and reward strategy to achieve the major goals of human resource management and organization.

\subsection{Research potential limitation}

- In this project, we are only concerned with overall commitment. However, there are three types of commitments in the fact. Therefore, the positive correlation between benefits system and job commitment would not be directly applicable for the all employees in company.

- Other limitation is that it is not possible to make causal inferences from data gathered in a field setting. The objective of this study was to look for any differences in employee's attitude under the two types of benefits, not to determine the reasons for those differences.

\subsection{Recommendations and Research prospect}

The following recommendations for future research are made on the base of the findings and limitation of the study:

The company can use Flexible benefits schemes to strengthen communication with staff, by understanding the organizational decision-making processes in adopting flexible benefits plans, comparisons can be made to understand 
the costs and benefits of such plans from the organization's points of view. We believe that our analysis of the impact of this type of benefits on organization commitment and intention to quit provides a useful framework for such efforts for administrators and academicians. Further, we submit that our integrated model offers insights into the decisions management makes about other HR innovations. Our model may have limited generality when it comes to some of the moderating factors such as type of commitment, however even these variables offer a platform for future work.

Other areas for future research include evaluating the effects of other workplace democratic and ethical practices on employees' work attitudes. Finally, job performance, turnover, and deviant behaviors have been found to be important outcomes of the effect of reward system in compensation management literature. The importance of these issues and them relationship with flexible benefits plan needs to be further elaborated in future research.

\section{References}

[1] Agarwala, T. (2003). Innovative human resource practices and organizational commitment: an empirical investigation. The International Journal of Human Resource Management, Vol. 14, Iss. 2, 175-197.

[2] Bentein, K., Vandenberghe, C.. Vandenberg, R,. and Stinglhamber, F. (2005). "The Role of Change in the Relationship between Commitment and Turnover: A Latent Growth Modeling Approach”. Journal of Applied Psychology, Vol . 90, Iss. 3, 468-482.

[3] Berg, P., Kalleberg, A. L., and Appelbaum, A. (2004). Balancing Work and Family: The Role of High-Commitment Environments, Industrial Relations. A Journal of Economy and Society, Vol. 42, Iss. 2, 168-188.

[4] Brashear, T. G., Manolis, C., and Brooks, C. M. (2005). The effects of control trust and justice on sales person turnover. Journal of Business Research, 58, 241-246.

[5] Bureau of labor statistics. (2005). Employee benefits in private industry," Journal of Business Re- search, no. 58.

[6] Bygren, M. (2004). Pay reference standards and pay satisfaction: what do workers evaluate their pay against?. Journal of Social Science Research, Vol . 33 , Iss. 2, $206-224$

[7] Cole, N. D., Flint. H. D. (2004). Perceptions of distributive and procedural justice in employee benefits: flexible versus traditional benefit plans. Journal of Managerial Psychology, Vol. 19, Iss. 1, $19-40$.

[8] Currall,S. C., Towler, A. J., Judge, T. A., and Kohn, L. (2005). pay satisfaction and organization outcomes. Personnel Psychology, vol. 58, 613- 640.

[9] Davis, A. E., and Kalleberg, A. (2006). Family friendly organization work and family programs. Journal of Work and occupations, 33, 191-223.

[10] DeConinck, J. B., and Stilwell, C.D. (2004). Incorporating organizational justice, role states, pay satisfaction and supervisor satisfaction in a model of turnover intentions. Journal of Business Research, Vol .57, Iss. 3, 225-231.

[11] Edgar, F., and Geare, A. (2004). Employee demographic in human resource management research. Journal of research and practice in human resource management, vol. 12, no. 1, 61-91.

[12] Feldman, J., and Landsman, D. L. (2009). The benefits of incentives. Talent Management Magazine, 22, 399- 410.

[13] Firth, L., Mellor, J., Moore, A., and Loquet, C. (2004). How can managers reduce employee intention to quit? Journal of Managerial Psychology, $19,170-187$.

[14] Govindarajulu, N., and Daily, F. B. (2004). Motivating employees for environmental improvement. Industrial Management \& Data Systems, Vol. 104 Iss. 4,364 - 372.

[15] Gyu-Chang, Y., Waldeck, E. N., and Rowley, C. (2008). The impact of flexible benefits on employee satisfaction: a study of the South Korean public sector. Journal of Society System Science, vol. 1. No. 1,67-83.

[16] Haar, T. M., and Spell, C. S. (2004). Program knowledge and value of work-family practices and organizational commitment. The International Journal of Human Resource Management, Vol. 15, Iss. 6, 1040-1055.

[17] Kossek, B. A., and Eaton, S. C. (2006). Job control and work family effectiveness. Journal of Vocational Behavior, 68, 347- 350.

[18] Kvaas, B. (2006). Work performance, effective commitment, and work motivation: the role of pay administration and pay level. Journal of Organization Behavior, vol. 27, iss. 3, 365- 385.

[19] Lee, S. H., Singhapakdi, A., and Too, T. T. (2008). Advantage of flexible over traditional benefits: a procedure justice explanation. Journal of applied research in quality of life, vol. 3, iss. 2, 107-125.

[20] Li-Ping, T., Luna, A. R., and Sutarso, T. (2005). From Income To Pay Satisfaction: The Love of Money and Pay Equity Comparison as Mediators and Culture (the United States and Spain) and Gender as Moderators. The Journal of the Iberoamerican Academy of Management, Vol. 3, Iss. 1, 07 - 26.

[21] Margaret, L., Williams, H., Brower, H., Ford, R. L., Williams, L. J., and Carraher, M. S. (2008). A comprehensive model and measure of compensation satisfaction. Journal of Occupational and Organizational Psychology, Vol. 81, Iss. 4, 639-668.

[22] Milkovich, G and Newman, J. M. (2005). Moderating effect of procedural justice in the relationship between participation in pay systems and personal outcomes. Journal Kemanusiaan bill, 9, 84-92.

[23] Narimawati, S. E. (2007). The influence of work satisfaction, organizational and turnover intention towards the performance. Journal of Applied Sciences Research, vol. 3. no. 7, 549-557.

[24] Nishikubo, K. Current situation and future direction of employees benefits. Japan labor review, vol. 7, no. 1, 4-145.

[25] Raymond, L.,. Hang-Yue, N., and Foley, S. (2006). Linking employees' justice perceptions to organizational commitment and intention to leave: The mediating role of perceived organizational support. Journal of Occupational and Organizational Psychology, Vol. 79, Iss. 1, 101-120.

[26] Richard, O. C., and Johnson, N. B. (2004). High performance work practices and HRM effectiveness. Journal of Business Strategies, vol 21, Iss. 2, 133.

[27] Scarpello,V., and Carraher, S. M. (2008). Are pay satisfaction and pay fairness the same construct?: A cross-country examination among the selfemployed in Latvia, Germany, the UK, and the USA. Baltic Journal of Management, Vol. 3 Iss. 1, 23 - 39.

[28] Sinclair,R. R., Hannigan, H. M., and Tetrick, L. E. (2005). Benefits coverage and employee attitude. Personnel Psychology, $163-165$.

[29] Swortzel, K. A., Taylor, W. N., and Scott, M. (2005). Demographic factors and the level of job satisfaction of extension agents. Journal of Southern Agricultural Education research, vol. 55, no. 1, 102-115.

[30] Warsi, S., Noor,F ., and Shamim, A. (2009). Study on relationship between organization commitment and its determinants among private sector employees of Pakistan. International review of business research papers, Vol. 5. no. 3, 399- 410.

[31] Williams, L. M., McDaniel, A. M., and Nguyen, N. T. (2006). A meta-analysis of the antecedents and consequences of pay level satisfaction. Journal of Applied Psychology, Vol. 91, Iss. 2, 392 - 413.

[32] Yousef, D. A. (2007). Organizational commitment a mediator of the relationship behavior with job satisfaction and performance in a non western country. Journal of Managerial Psychology, 15, 6-24.

[33] Zhaohonga, L., Kellyb, J., and Trenberth, L. (2011). Antecedents and consequences of the introduction of flexible benefit plans in China. The International Journal of Human Resource Management, Vol. 22, Iss. 5, 1128-1145. 